\title{
AVALIAÇÃO DE HERBICIDAS NO CONTROLE DE PLANTAS DANINHAS NA CULTURA DA SOJA
}

\author{
A.C. de BARROS ${ }^{1}$, F.S.A. MATOS ${ }^{2}$ e C.T. NETTO ${ }^{2}$
}

RESUMO

\begin{abstract}
Foi conduzido em Serranópolis, GO, um ensaio objetivando avaliar a eficiência e a seletividade de herbicidas no controle de plantas daninhas na cultura da soja (Glycine max (L.) Merril), utilizando-se os seguintes tratamentos: A) 100 g/ha de imazethapyr (ácido 2-[4,5-dihidro-4-metil-4-(1metiletil)-5-oxo-lH-imidazol-2-ilol-5-etil-3-piridinacarbox ilico) + surfactante, a $0,25 \% v / v$; B) tratamento A e 15 dias após, $230 \mathrm{~g} / \mathrm{ha}$ de sethoxydim (2-1-etoximino-butil-52(etiltio)-propil-3-hidroxi-2-ciclohexeno-1-ona) + óleo mineral, a $0,25 \% \mathrm{v} / \mathrm{v}$; C) $230 \mathrm{~g} / \mathrm{ha}$ de sethoxydim + óleo mineral, a $0,25 \% \mathrm{~V} / \mathrm{V}$; D) $480+200+230 \mathrm{~g} / \mathrm{ha}$ de bentazon (3-isopropil-2,1,3-benzotiadiazinona-(4)-2,2 -dióxido) + fomesafen (5-(2-cloro-4-(trifluorometil-fenoxi)N-metilsulfonil2nitrobenzamida) + sethoxydim + óleo mineral, $0,25 \% \mathrm{v} / \mathrm{v} ; \mathrm{E}$ ) $150 \mathrm{~g} / \mathrm{ha}$ de imazaquim (2-[4,5-dihidro-4-metil-4-(1metiletil)-5-oxo-1H-imidazol-2-ilo]-3-quinoli nata rboxí liso) pré-e e $230 \mathrm{~g} / \mathrm{ha}$ de sethoxydim + óleo mineral, $0,25 \% \mathrm{v} / \mathrm{v}$;
\end{abstract}

F) $250 \mathrm{~g} / \mathrm{ha}$ de fomesafen $+187 \mathrm{~g} / \mathrm{ha}$ de fluazifop-p-butil (butil-(R)-2-(4-(5-trifluorometil-2-piridiloxi)-fenoxi)-propionato) + surfactante a $0,2 \% \mathrm{v} / \mathrm{v} ; \mathrm{G}) 120 \mathrm{~g} /$ ha de imazethapyr + surfactante a $0,2 \% \mathrm{v} / \mathrm{v} ; \mathrm{H})$ testemunha capinada; I) testemunha não capinada. $\mathrm{O}$ delineamento experimental foi de blocos ao acaso, com quatro repetições. O capim-custódio (Pennisetum setosum (Swartz) L. Rich.) foi eficientemente controlado por todos os tratamentos químicos, enquanto a falsa-serralha (Emilia sonchifolia DC.) foi somente pelo tratamento D. O capim-carrapicho (Cenchrus echinatus L.) por C, D, E e F. O joá-de-capote (Nicandra physaloides (L) Pers.) por $\mathrm{D}, \mathrm{F}$ e G. Ocorreram injúrias iniciais às plantas de soja, nos tratamentos D, E e F. As alturas de plantas e de inserção da primeira vagem, além do rendimento de grãos, não foram influenciados significativamente pelos herbicidas. Palavras-chave: herbicidas, plantas daninhas, injúrias.

\section{SUMMARY}

\section{EVALUATION OF HERBICIDES IN THE CONTROL OF WEEDS IN THE SOYBEAN CROP}

An experiment was carried out in Serranópolis, State of Goiás, Brazil, aiming to evaluate herbicides efficiency in weeds control and selectivity of the same ones for soybean crop (Glycine $\max ($ L.) Merril). The following treatments were utilized: A) $100 \mathrm{~g} / \mathrm{ha}$ of imazethapyr + surfactant at $0,25 \% \mathrm{v} / \mathrm{v} ; \mathrm{B})$ treatment $\mathrm{A}$ and 15 days after $230 \mathrm{~g} / \mathrm{ha}$ of sethoxydim + mineral oil at $0,25 \% \mathrm{v} / \mathrm{v} ;$ C) $230 \mathrm{~g} / \mathrm{ha}$ of sethoxydim + mineral oil at $0,25 \% \mathrm{v} / \mathrm{v}$; D) $480+200+230$

1 Eng $^{\circ}$ Agr $^{\circ}$, Pesquisador da EMGOPA/Estação de Pesquisa "Olavo Sérvulo de Lima", Cx. Posta1 211.75.800-000 - Jataí, GO.

2 Eng $^{\circ}$ Agr $^{\circ}$, Pesquisador da Area de Desenvolvimento de Produtos Agrícolas/CYANAMID QUIMICA DO BRASIL LTDA., Av. Imperatriz Leopoldina, 86. 01.015-000 - São Paulo, SP. $\mathrm{g} / \mathrm{ha}$ of bentazon + fomesafen + sethoxydim + mineral oil at $0,25 \% \mathrm{v} / \mathrm{v}$; E) $150 \mathrm{~g} / \mathrm{ha}$ of imazaquim (pre-emergent) and 230 $\mathrm{g} / \mathrm{ha}$ of sethoxydim + mineral oil at $0,25 \% \mathrm{v} / \mathrm{v} ; \mathrm{F}) 250 \mathrm{~g} / \mathrm{ha}$ of fomesafen $+187 \mathrm{~g} / \mathrm{ha}$ of fluazifop-p-butil + surfactant at $0,2 \% \mathrm{v} / \mathrm{v}$; G) $120 \mathrm{~g} / \mathrm{ha}$ of imazethapyr + surfactant at $0,25 \%$ $\mathrm{v} / \mathrm{v} ; \mathrm{H})$ control with hoeing; I) control without hoeing. The experimental design was randomized blocks with four replications. "Capim-custódio" (Pennisetum setosum (Swartz) L. Rich.) was efficiently controlled by all the chemical treatments where as "Falsa-serralha" (Emilia sonchifolia DC.) only by the treatment D. "Capim-carrapicho" (Cenchrus echinatus L.) by G, D, F. "Joá-de-capote" (Nicandra physaloides (L.) Pets.) by D, F and G. Initial injuries were found in

Planta Daninha, v. 10, n. 1/2, 1992. 
soybean plants in the treatments D, E and F. Neither height of plants and insertion of the first pod nor grain yield was

\section{INTRODUÇÃO}

A cultura da soja vem se expandindo na região do Sudoeste de Goiás, firmando-se cada vez mais como geradora de riqueza. No entanto, em razão de dificuldades na aquisição de sementes certificadas para atender à demanda, a utilização de grãos como sementes vem sendo empregada, nos últimos anos, contribuindo para a disseminação mais rápida de plantas daninhas e para o aparecimento de novas espécies na região (3).

Geralmente, as gramíneas têm provocado maiores danos à cultura da soja, quando comparadas com invasoras dicotiledôneas. $\mathrm{O}$ capim-custódio (Pennisetum setosum) e o capim-colchão (Digitaria sp.) são de ocorrência bastante freqüente nas principais regiões produtoras de soja do Estado de Goiás (1).

O controle de invasoras na cultura da soja é indispensável, pois as plantas daninhas são responsáveis por grandes perdas no rendimento de grãos e na qualidade do produto colhido, além de acarretar embuchamento na auto-motriz, reduzindo o coeficiente técnico.

Tendo em vista que as plantas daninhas podem ocorrer em manchas, as aplicações de herbicidas em pós-emergência, apenas nas faixas afetadas, podem reduzir o custo da produção.

A utilização do ingrediente ativo, sethoxydim está amplamente difundida, comprovando a sua eficiência $(2,9)$, e (7). O imazethapyr tem se destacado no controle de plantas daninhas dicotiledôneas, com ação também no controle de gramíneas $(5,6)$.

Objetivou-se neste experimento estudar a eficiência de herbicidas no controle e na seletividade de plantas daninhas à cultura de soja.

\section{MATERIAIS E MÉTODOS}

O experimento foi conduzido na área de produção de sementes da EMGOPA, em Serranópolis, GO, no ano agrícola de 1989/90, num latossolo vermelho-amarelo, de significantly influenced by the herbicides.

Key words: herbicides, weeds, injuries. textura argilosa, com $49 \%$ de argila e 3,83\% de matéria orgânica. Efetuou-se o plantio da soja cv. EMGOPA 304, em $13 / 11 / 1989$, aplicando-se nos sulcos de plantio a adubação de $500 \mathrm{~kg} / \mathrm{ha}$ da fórmula 0-20-10. O delineamento experimental utilizado foi o de blocos ao acaso, com nove tratamentos e quatro repetições.

$\mathrm{O}$ imazaquim foi aplicado em pré-emergência, no dia da semeadura da soja, e os demais produtos em pós-semeadura, quando as plantas daninhas apresentavam de 4 a 6 folhas e a soja no $3^{\circ}$ trifólio. Estas aplicações foram efetuadas em 08/12/89, das 09:00 às 09:45 horas, com umidade relativa e temperatura do ar de $85 \%$ e $24,2^{\circ} \mathrm{C}$, respectivamente. Para aplicação dos produtos, utilizou-se um pulverizador costal, pressurizado a $\mathrm{CO} 2, \operatorname{com} 3,0 \mathrm{~kg} / \mathrm{cm}^{2}$ de pressão, barra munida de quatro bicos, tipo leque "8003", gastando-se 300 litros de calda/ha.

As parcelas foram constituídas por sete linhas de soja com 7,0 m de comprimento, espaçadas de 0,50 m entre si, enquanto a área útil constou de duas linhas, desprezando-se 1,0 $\mathrm{m}$ nas extremidades de cada parcela.

As precipitações pluviométricas, em $\mathrm{mm}$ registradas por decêndio em Jataí, GO, no período de novembro de 1989 a abril de 1990, estão relacionadas no Quadro 1.

Para a avaliação de controle utilizou-se uma escala conceitual, onde acima de 95 equivale a um controle excelente; 85 a 94, bom controle; 65 a 84, controle mediano ou aceitável na prática e menos de 65 , baixo controle. A fitotoxicidade foi avaliada, também, através da mesma escala, onde $\mathrm{O}$ equivale à ausência de injúrias e 100, morte total da cultura. na colheita, efetuou-se avaliação visual da facilidade da colheita mecânica, levando-se em consideração a cobertura da área e porte das plantas daninhas. Utilizou-se uma escala arbitrária proposta por Souza (8), atribuindo-se conceitos excelente, muito bom, regular e impraticável. Mediramse, ainda, altura de plantas, altura de inserção da primeira vagem e rendimento de grãos colhidos.

As plantas daninhas dicotiledôneas mais freqüentes foram: joá-de-capote (Nicandra physaloides) e falsa-serralha (Emilia sonchifolia), enquanto as gramíneas foram capimcustódio (Pennisetum se to sum) e capim-carrapicho (Cenchrus echinatus).

QUADRO 1 - Precipitaçôes pluviométricas (em mm), por decêndio, registradas em Jataí, GO, no período de novembro de 1989 a abril de 1990.

\begin{tabular}{l|r|r|r|r|r|r}
\hline \multirow{2}{*}{ Decêndios } & \multicolumn{2}{|c|}{1989} & \multicolumn{4}{c}{1990} \\
\cline { 2 - 7 } & novembro & dezembro & janeiro & fevereiro & março & abril \\
\cline { 2 - 7 } $1^{2}$ & 62,5 & 181,6 & 55,3 & 25,5 & 39,6 & 24,8 \\
$2^{0}$ & 59,4 & 113,2 & 20,8 & 53,9 & 6,4 & 51,9 \\
$3^{2}$ & 27,4 & 94,4 & 46,1 & 95,4 & 38,5 & 0,0 \\
\hline Total & 149,3 & 389,2 & 122,2 & 174,8 & 84,5 & 76,7
\end{tabular}




\section{RESULTADOS E DISCUSSÃO}

Imazethapyr + surfactante, a $0,25 \% \mathrm{v} / \mathrm{v}$, na dose de 120 $\mathrm{g} / \mathrm{ha}$; o fomesafen + fluazifop-p-butil + surfactante, a $0,2 \%$ $\mathrm{v} / \mathrm{v}$ e o bentazon + fomesafen + sethoxydim + óleo mineral, a $0,25 \% \mathrm{v} / \mathrm{v}$, propiciaram bom controle do joá-de-capote, obtendo-se conceito mínimo 89, nas três avaliações (Quadro 2). No entanto, imazethapyr (100 g/ha) + surfactante, a $0,25 \%$ $\mathrm{v} / \mathrm{v}$; sethoxydim (230 g/ha) + óleo mineral, a $0,25 \% \mathrm{v} / \mathrm{v}$, aplicado 15 dias após, imazaquim, em pré-e, e sethoxydim + óleo mineral, a $0,25 \% \mathrm{v} / \mathrm{v}$, em pós-e, proporcionaram controle mediano (65 a 84) dessa infestante, porém aceitável na prática. A aplicação isolada do herbicida sethoxydim + óleo mineral proporcionou baixo controle (menos de 65) desta espécie, pois trata-se de um graminicida. Para falsa-serralha, o melhor resultado foi obtido com aplicação de bentazon + fomesafen + sethoxydim com óleo mineral, a $0,25 \% \mathrm{v} / \mathrm{v}$, com conceito mínimo 86 nas três avaliações, vindo a seguir fomesafen + fluazifop-p-butil + surfactante, a $0,2 \%$ v/v e, ainda, imazethapyr com surfactante, a $0,25 \% \mathrm{v} / \mathrm{v}$, na maior dose, sendo que os demais tratamentos obtiveram níveis de controle mediano a baixo.

O capim-custódio foi eficientemente controlado por todos os herbicidas testados, que proporcionaram conceitos de 89 a 100. Resultados semelhantes foram obtidos por Barros et al.(4), com a utilização de sethoxydim no controle dessa espécie infestante. O capim-carrapicho foi controlado com um conceito mínimo 84, por todos os produtos, exceto imazethapyr, aplicado nas doses de 100 a $120 \mathrm{~g} / \mathrm{ha}$, que propiciaram menor controle da referida gramínea, porém aceitável na prática. Resultados semelhantes foram obtidos por Barros (2) com aplicação de sethoxydim no controle do capim-carrapicho.

Deve-se considerar que o ano agrícola 1989/90 foi atípico, com precipitações pluviométricas intensas em dezembro de 1989 e menos chuvosa, com distribuição irregur lar, nos meses seguintes, o que pode ter influenciado negativamente nos resultados obtidos.

Observou-se que, ao aplicar sethoxydim, 15 dias após imazethapyr, as plantas daninhas remanescentes encontravam-se mais desenvolvidas e protegidas pela soja, influenciando de maneira negativa os resultados de controle das mesmas.

$\mathrm{Na}$ colheita da soja, verificou-se que os tratamentos testados apresentaram condições de colheita de muito boa a excelente, exceto o tratamento sethoxydim com óleo mineral, que não controlou as plantas daninhas dicotiledôneas, além da testemunha não capinada, onde as invasoras sobrepujaram a cultura da soja, influencíando negativamente no rendimento de grãos colhidos (Quadro 3). Verificourse que a testemunha não capinada apresentou valores estatisticamente inferiores a todos os tratamentos. Observou-se que a maior produção de grãos foi na testemunha capinada, porém não diferiu signifi-

QUADRO 2 - Resultados médios de controle de plantas daninhas ${ }^{(1)}$, obtidos no ensaio de herbicidas em Serranópolis, GO, 1989/90.

\begin{tabular}{|c|c|c|c|c|c|c|c|c|c|c|c|c|c|}
\hline \multirow{3}{*}{ Tratamentos } & \multirow{3}{*}{ Dose $(\mathrm{g} / \mathrm{ha})$} & \multicolumn{3}{|c|}{ P.setosum ${ }^{(2)}$} & \multicolumn{3}{|c|}{ C.echinatus $^{(3)}$} & \multicolumn{3}{|c|}{ N.physaloides ${ }^{(4)}$} & \multicolumn{3}{|c|}{ Esonchifolia $^{(5)}$} \\
\hline & & \multicolumn{12}{|c|}{ DAP $^{6}$} \\
\hline & & 45 & 56 & 79 & 45 & 56 & 79 & 45 & 56 & 79 & 45 & 56 & 79 \\
\hline A- Imazethapyr + surfactante a $0,25 \% \mathrm{v} / \mathrm{v}$ & 100 & 92 & 91 & 91 & 86 & 80 & 70 & 73 & 76 & 75 & 70 & 67 & 62 \\
\hline $\begin{array}{l}\text { B- Imazethapyr + surfactante a } 0,25 \% \mathrm{v} / \mathrm{v} \text { e } \\
\text { sethoxydim + óleo mireral a } 0,25 \% \mathrm{v} / \mathrm{v}\end{array}$ & 100 e 230 & 98 & 95 & 96 & 94 & 85 & 84 & 78 & 71 & 62 & 77 & 66 & 60 \\
\hline C- Sethoxydim + óleo mireral a $0,25 \% \mathrm{v} / \mathrm{v}$ & 230 & 100 & 99 & 100 & 100 & 100 & 100 & 38 & 55 & 47 & 40 & 55 & 52 \\
\hline $\begin{array}{l}\text { D- Benzaton + fomesafen }+ \text { sethoxydim + } \\
\text { óleo mineral a } 0,25 \% \mathrm{v} / \mathrm{v}\end{array}$ & $480+200+230$ & 100 & 95 & 98 & 100 & 100 & 99 & 97 & 100 & 92 & 95 & 92 & 86 \\
\hline $\begin{array}{l}\text { E- Imazaquim + sethoxydim + óleo } \\
\text { mineral a } 0,25 \% \mathrm{v} / \mathrm{v}\end{array}$ & 150 e 230 & 100 & 100 & 100 & 96 & 99 & 93 & 76 & 89 & 82 & 84 & 80 & 67 \\
\hline $\begin{array}{l}\text { F- Fomesafen + fluazifop-p-butil + } \\
\text { surfactante a } 0,2 \% \text { v/v }\end{array}$ & $250+187$ & 90 & 89 & 90 & 91 & 88 & 93 & 96 & 94 & 95 & 99 & 92 & 81 \\
\hline G- Imazethapyr + surfactante a $0,25 \% \mathrm{v} / \mathrm{v}$ & 120 & 100 & 95 & 96 & 91 & 87 & 80 & 92 & 96 & 89 & 85 & 82 & 75 \\
\hline H- Testemunha capinada & - & 100 & 100 & 100 & 100 & 100 & 100 & 100 & 100 & 100 & 100 & 100 & 100 \\
\hline I - Testemunha nāo capinada & - & 0 & 0 & 0 & 0 & 0 & 0 & 0 & 0 & 0 & 0 & 0 & 0 \\
\hline $\begin{array}{l}\mathrm{N}^{2} \text { plantas daninhas } / \mathrm{m}^{2} \text { na testemunba } \\
\text { não capinada }\end{array}$ & - & 8 & 5 & 3 & 9 & 10 & 8 & 21 & 15 & 13 & 4 & 4 & 2 \\
\hline
\end{tabular}

(1) Escala de avaliaçāo através de conceitos de 0 a 100 , onde: 0 representa nenbum controle; 100 equivale a controle total das plantas daninhas

(2) capim-custódio

(3) capim-carrapicho

(4) joá-de-capote

(5) falsa-serralha

(6) dias após o plantio 
cativamente dos tratamentos químicos, excetuando-se sethoxydim com óleo mineral e imazethapyr (100 g/ha) + surfactante com sethoxydim + óleo mineral, aplicado 15 dias após imazethapyr.
Foi observado, na colheita da soja, que as parcelas tratadas com imazethapyr a $100 \mathrm{~g} / \mathrm{ha}$ (i.a.) apresentaram conceito muito bom na avaliação de pré-colheita (Quadro 4), contrastando com as avaliações anteriores que apresentaram

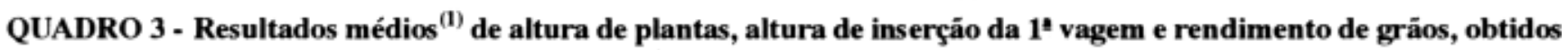
no ensaio de herbicidas em Serranópolis, GO, 1989/90.

\begin{tabular}{|c|c|c|c|c|}
\hline Tratamentos & Dose (g/ha) & $\begin{array}{c}\text { Altura de } \\
\text { planta }(\mathrm{cm})\end{array}$ & $\begin{array}{c}\text { Altura de } \\
\text { inserçäo da } \\
\mathbf{1}^{\mathbf{a}} \text { vagem }(\mathrm{cm})\end{array}$ & $\begin{array}{l}\text { Rendimento de } \\
\text { grãos (kg/ha) }\end{array}$ \\
\hline A- Imazethapyr + surfactante a $0,25 \% \mathrm{v} / \mathrm{v}$ & 100 & $82 a^{(1)}$ & $17 \mathrm{ab}$ & $2.270 \mathrm{ab}$ \\
\hline $\begin{array}{l}\text { B- Imazethapyr + surfactante a } 0,25 \% \mathrm{v} / \mathrm{v} \text { e } \\
\text { sethoxydim + óleo mireral a } 0,25 \% \mathrm{v} / \mathrm{v}\end{array}$ & 100 e 230 & 78 a & $17 \mathrm{ab}$ & $1.752 \mathrm{~b}$ \\
\hline C- Sethoxydim + óleo mireral a $0,25 \% \mathrm{v} / \mathrm{v}$ & 230 & 82 a & $16 \mathrm{ab}$ & $1.683 \mathrm{~b}$ \\
\hline $\begin{array}{l}\text { D- Benzaton }+ \text { fomesafen }+ \text { sethoxydim }+ \\
\text { óleo mineral a } 0,25 \% \mathrm{v} / \mathrm{v}\end{array}$ & $480+200+230$ & 80 a & $15 \mathrm{~b}$ & $2.293 \mathrm{ab}$ \\
\hline $\begin{array}{l}\text { E- Imazaquim + sethoxydim + óleo mineral } \\
\text { a } 0,25 \% \mathrm{v} / \mathrm{v}\end{array}$ & 150 e 230 & 80 a & $17 \mathrm{ab}$ & $2.120 \mathrm{ab}$ \\
\hline $\begin{array}{l}\text { F- Fomesafen + fluazifop-p-butil + } \\
\text { surfactante a } 0,2 \% \text { v/v }\end{array}$ & $250+187$ & 80 a & $20 \mathrm{ab}$ & $2.140 \mathrm{ab}$ \\
\hline G- Imazethapyr + surfactante a $0,25 \% \mathrm{v} / \mathrm{v}$ & 120 & 82 a & $17 \mathrm{ab}$ & $2.208 \mathrm{ab}$ \\
\hline H- Testemunha capinada & - & 81 a & $16 \mathrm{ab}$ & $2.737 \mathrm{a}$ \\
\hline I - Testemunha não capinada & - & 83 a & 22 a & $837 \mathrm{c}$ \\
\hline CV. $(\%)$ & - & 9,9 & 14,1 & 13,9 \\
\hline D.M.S. & - & 10 & 6 & 672 \\
\hline
\end{tabular}

(1) Médias na coluna, seguidas das mesmas letras, nāo diferem significativamente entre si, ao nível de $5 \%$ de probabilidade pelo teste de Tukey.

QUADRO 4 - Resultados médios de facilidade de colheita mecânica e fitotoxidade à cultura da soja, aos 45 , 56 e 79 dias após o plantio (DAP), obtidos no ensaio de herbicidas em Serranópolis, GO, 1989/90.

\begin{tabular}{|c|c|c|c|c|c|}
\hline \multirow{3}{*}{ Tratamentos } & \multirow{3}{*}{ Dose $(\mathrm{g} / \mathrm{ha})$} & \multirow{3}{*}{$\begin{array}{c}\text { Avaliação de pré-colheita } \\
\text { (facilidade de colheita } \\
\text { mecânica) }\end{array}$} & \multicolumn{3}{|c|}{ Fitotoxidade } \\
\hline & & & \multicolumn{3}{|c|}{ DAP } \\
\hline & & & 45 & 56 & 79 \\
\hline A- Imazethapyr + surfactante a $0,25 \% \mathrm{v} / \mathrm{v}$ & 100 & Muito boa & $0^{(2}$ & 0 & 0 \\
\hline $\begin{array}{l}\text { B- Imazethapyr + surfactante a } 0,25 \% \text { v/v e } \\
\text { sethoxydim + óleo mireral a } 0,25 \% \mathrm{v} / \mathrm{v}\end{array}$ & 100 e 230 & Muito boa & 0 & 0 & 0 \\
\hline C- Sethoxydim + óleo mireral a $0,25 \% \mathrm{v} / \mathrm{v}$ & 230 & Regular & 0 & 0 & 0 \\
\hline $\begin{array}{l}\text { D- Benzaton }+ \text { fomesafen }+ \text { sethoxydim }+ \\
\text { óleo mineral a } 0,25 \% \mathrm{v} / \mathrm{v}\end{array}$ & $480+200+230$ & Excelente & 10 & 0 & 0 \\
\hline $\begin{array}{l}\text { E- Imazaquim + sethoxydim + óleo mineral } \\
\text { a } 0,25 \% \mathrm{v} / \mathrm{v}\end{array}$ & 150 e 230 & Muito boa & 5 & 0 & 0 \\
\hline $\begin{array}{l}\text { F- Fomesafen + fluazifop-p-butil + } \\
\text { surfactante a } 0,2 \% \mathrm{v} / \mathrm{v}\end{array}$ & $250+187$ & Excelente & 10 & 0 & 0 \\
\hline G- Imazethapyr + surfactante a $0,25 \% \mathrm{v} / \mathrm{v}$ & 120 & Excelente & 0 & 0 & 0 \\
\hline H- Testemunha capinada & - & Excelente & 0 & 0 & 0 \\
\hline I - Testemunha não capinada & - & Excelente & 0 & 0 & 0 \\
\hline
\end{tabular}

(1) Escala de facilidade de colbeita: excelente, muito boa, regular e impraticável

(2) Escala de fitotoxicidade: $0=$ ausência de sintomas fitotóxicos às plantas de soja; $100=$ danos totais à produção de grăos 
controle mediano do joá-de-capote e capim-carrapicho (Quadro 2). Não houve diferença significativa desse com os demais tratamentos químicos em termos de rendimento de grãos. Isso ressalta a importância de se ter um bom stand de plantas, que propicia o rápido fechamento da soja, abafando, assim, as plantas daninhas remanescentes. Os tratamentos químicos testados não influenciaram significativamente a altura de plantas. No entanto, a altura de inserção da primeira vagem, no tratamento bentazon + fomesafen + sethoxydim com óleo mineral, apresentou valor estatisticamente inferior à testemunha não capinada, porém não deferiu significativamente dos demais tratamentos.

Constatou-se que apenas os tratamentos bentazon + fomesafen + sethoxydim com óleo mineral, imazaquim e sethoxydim aplicado 25 dias após, além de fomesafen + fluazifop-p-butil + surfactante, a $0,2 \% \mathrm{v} / \mathrm{v}$, apresentaram na fase inicial, níveis baixos de fitotoxicidade às plantas de soja; entretanto, a partir da segunda avaliação visual, não foram observadas injúrias à cultura da soja (Quadro 4).

Sethoxydim aplicado isoladamente e após o imazethapyr proporcionaram os mais baixos níveis de controle de folhas largas, possivelmente contribuindo para a obtenção de níveis de produtividade mais baixas em relação aos outros tratamentos químicos, agravado ainda, pela agressividade do joá-de-capote. Entretanto, não houve diferenças estatísticas entre os tratamentos químicos.

\section{AGRADECIMENTOS}

Os autores expressam agradecimentos ao Técnico Agrícola Vicente Paulo Bernardo Lima, pela colaboração na implantação e condução deste ensaío; ao Engenheiro Agrônomo Gil Santos, Pesquisador da Area de Métodos Quantitativos da EMGOPA, pelas análises estatísticas dos resultados; à Bibliotecária Patrícia de Oliveira Portela, pela colaboração nas citações bibliográficas.

\section{LITERATURA CITADA}

1- BARROS, A.C. de. Eficiência de herbicidas pós-emergentes no controle de gramíneas na cultura da soja. Goiânia, 1989a. 8p. (EMGOPA. Comunicado Técnico, 18).
2- BARROS, A.C. de. Ef ic iência e se le ti vida de de herbicidas pós-emergentes no controle do timbete (Cenchrus echinatus L.) na cultura da soja. Goiânia: EMGOPA, 1989b. 9p. (EMGOPA. Comunicado Técnico, 15).

3 - BARROS, A.C. de.; EICHLER, V. Flora invasora na cultura da soja na re gião do Sudeste Goiano. Goiânia: EMGOPA, 1986. 5p. (EMGOPA. Comunicado Técnico, 10).

4 - BARROS, A.C. de.; EICHLER, V.; SILVA, R.J.M. da. Efeitos do controle integrado do capim-custódio (Pennisetum setosum (Swartz) L. Rich.) na cultura da soja no Sudeste Goiano. Goiânia: EMGOPA, 1989. 11p. (EMGOPA. Boletim de Pesquisa, 14).

5 - BRAGA, O. Eficiência do imazethapyr, aplicado em pós-emergência, no controle de monocotiledôneas e dicotiledôneas na cultura da soja (Glycine max). In: CONGRESSO BRASILEIRO DE HERBICIDAS E PLANTAS DANINHAS, 17., 1988, Piracicaba. Resumos... Ribeirão Preto : Legis Sununa, 1988. p. 154-155.

6 - DURINGAN, J.C.; LUSVARGHI, H.W. Eficiência do imazethapyr, aplicado em pós-emergência "precoce", para o controle de plantas daninhas na cultura da soja (Glycine max). In: CONGRESSO BRASILEIRO DE HERBICIDAS E PLANTAS DANINHAS, 17., 198\$, Piracicaba. Resumos.. Ribeirão Preto : Legis Summa, 1988. p. 158-159.

7 - MELHORANÇA, A.L. Efeitos dos he rbicidas pós-emergentes no desenvolvimento e na produção de grãos da soja. In: SEMINÁRIO NACIONAL DE PESQUISA DA SOJA, 3., 1984, Campinas. Anais... Londrina : EMBRAPA/CNPSo, 1984. p. 558-564.

8 - SOUZA, I.F. de. Misturas de herbicidas pré-emergentes para o controle de plantas daninhas em soja, sob condições de cerrado. Belo Horizonte : EPAMIG, 1986. 19p. (Mimeografado).

9 - SOUZA, I.F. DE.; REZENDE, A.M.; LACA-BUENDIA, J.P.; YOSHIURA, M. Avaliação de angustifoliadicidas na cultura da soja em Minas Gerais. Planta Daninha, Campinas, 9(1/2): 1-13, 1985. 